\title{
Effect of Debate Method on Nursing Ethical Value and Learning Outcomes
}

Jihyun Kim*

Department of Nursing Science, Baekseok University, Cheonan-330-705, Korea; Jhkimrn@bu.ac.kr

\begin{abstract}
This study was aimed to identify the effects of debated teaching methods on nursing ethical value and learning outcomes. Learning outcomes consisted of teamwork skill, problem solving ability, and communication ability. Data were collected from 128, 2nd grade students of nursing college located in C city of Chungnam province in Korea. The data were analyzed using paired t-test to compare means pre and post average of the variables. Nursing ethical value was changed to higher $(3.75 \pm 0.33, t=-2.687, p=0.008)$ and problem solving ability was moved to higher, significantly $(3.79 \pm 0.38, t=-3.315$, $\mathrm{p}=0.001)$. Teamwork skill was changed $(3.94 \pm 0.45, \mathrm{t}=-1.366, \mathrm{p}=0.174)$. Communication ability was moved to higher $(3.74 \pm 0.36, t=-1.536, p=0.127)$. After the class, nursing students' view point was moved to deontology from utilitarianism. And problem solving ability was improved. Debate methods is a good teaching model and very useful for ethic class.
\end{abstract}

Keywords: Communication Ability, Debate Teaching Method, Ethical Value, Problem Solving Ability Teamwork Skill

\section{Introduction}

Ethical and moral judgment of nurse as a medical team is getting important. Nurses are often faced ethical dilemma situation and must make a ethical decision. Ethical dilemma occurs when options include conflicting moral claims. According to Bauchamp and Childress, a conflict can be experienced when there is evidence to indicate that a certain act is morally right and evidence to indicate that the act is morally wrong, but no evidence is conclusive ${ }^{7}$. For example, a terminally ill patient has been cared on a bed in a critical care unit and there's no bed in that unit, while 30 years old man by car accident must be admitted to critical care unit.

Another patient in his or her 30s may die because of not receiving timely acute care. Is it ethically right to keep a hopeless patient in an intensive care unit for ongoing treatment? Or is it not? It could be an act of ignoring a patient's right to live to give up treating him or her due to no chance of survivability. Medical care providers often fall into this kind of many ethical dilemmas related to euthanasia, abortion, cerebral death and organ transplant. Two ethical views are utilitarianism and deontology. Good is delight and the best choice is the greatest happiness of the greatest number in utilitarianism developed by J.S. Mill and J. Bentam. But deontology developed by Kant, good is actions may be right or wrong regardless of the outcome. Nurses also may have different attitudes, but have a guideline to be on a side for decision making ${ }^{6}$.

When a nurse faces this type of ethical issue in clinical setting but does not have clear yardstick for judgment due to no prior experiences of a similar situation to this before, she must have difficulty making ethical decision. It was reported that $36.7 \%$ of nurses had experienced a conflict with biomedical ethics ${ }^{8}$. According to the data of Ann, Kim, Cho, Eom, and Lee's research, nurses reported that they had most experienced problems especially with nursing ethics related to patient's confidentiality ${ }^{9}$. It also reported that many nurses had not had the education on ethical decision making and thus highly demanded ethical guidelines for nurses ${ }^{9}$. Accordingly, Korean Nurses Association organized Biomedical Ethics Committee to tackle the ethical dilemmas that clinical nurses face and established 2007 Ethical Guidelines for Nurses. To help nurses have better ability to make decision on ethical issues, it is effective to open the course of nursing ethics in nursing schools and teach them how to handle the issues related to nursing ethics ${ }^{2}$.

${ }^{*}$ Author for correspondence 
Decision making is fulfilled by cooperation of health care team. Thus it is very important to achieve teamwork skill, problem solving ability and communication ability to resolve ethical dilemmas rationally for nurses. These abilities are regarded as learning outcomes achieved through nursing education coursework, generally and debated teaching method is effective to enhance the abilities.

It has been known that debate-based learning using CEDA methodology in nursing ethics education is effective in improving nursing students' ethical value and moral judgment ${ }^{6}$. Group debate facilitates nursing students in solving given ethical dilemmas that can arise in a clinical setting because they can approach the issues from various points of view. Besides CEDA, there are many other debate methods. They include parliamentary debate, pyramid debate and panel debate. Sometime, there are ethical situations that cannot be properly addressed by CEDA debate method. Therefore, it is more effective to introduce more diverse debate methods and provide nursing students with a chance to experience ethical decision making. This study was aimed to identify the effects of debated teaching methods on nursing ethical value and learning outcomes.

\section{Methods}

\subsection{Research design}

This study was a research to identify the effect of debate methods on change of nursing ethical values and learning outcomes. 5 different debate and discussion methods were used to solve the nursing ethical problems in Nursing Ethic Class in 2013, 2nd semester. The debate and discussion methods included CEDA, Pyramid, mock court, panel discussion and parliamentary debate. For effective debating, 7-8 students constituted one group and carried out finding the resolution about ethical issues assigned.

The students had a 6-week online debate and a faceto-face debate. Their nursing ethical values and learning outcomes were measured before and after the debates, and compared with each other. Key dilemmatic situations related to nursing ethics in clinical setting were given to the student as follows:

- Abortion-related,

- mercy killing-related,

- brain death-related,
- organ transplant-related,

- Drug abuse and misuse of a coworker and

- nursing a terminal patient.

The student had liberty to choose debating method depending on each topic. The students chose mock trial for Issue 1, CEDA for Issue 2 and 3, pyramid debate for Issue 4, the panel debate of hospital ethics committee for Issue 5 and parliamentary debate for Issue 6.

\subsection{Subjects and data collection}

The subjects of this research are enrolled nursing students who took a nursing ethics class in a nursing college located in C city, Chungcheong-namdo province in Korea. Researcher conducted a convent sampling of 128 students who listened the object, procedure, and method of the research and agreed to participate. The participants were notified that (i) all of the collected data were only used for research purpose and would be disposed after the experiment, (ii) their participation had no effect on their school record, and (iii) they could stop the experiment anytime during the course. The students signed on and submitted consent forms on their will. One survey before debate, with questionnaires was conducted from October the $1^{\text {st }}$ to the $4^{\text {th }}, 2013$. The other survey after debate was carried out from November the $25^{\text {th }}$ to the $29^{\text {th }}, 2013$.

\subsection{Research tool}

This research used a self-reported questionnaire. To identify the nursing students' ethical vale, this study used a tool that was originally developed by Lee (1990) and modified by Jung $(1995)^{5}$. The question items included human life, relationship with patients, nursing jobs, and cooperation. Chronbach alpha of the internal reliability of the data on nursing ethical values was .72. Low points means attitude of utilitarianism and high points means attitude of deontology. For learning outcomes, this study used the variables as teamwork skill, problem solving ability, communication ability. To check teamwork skill, the tool developed by Cannon-bower(1995)was used ${ }^{3}$, with Chronbach alpha of .84. The abilities to solve problems were investigated by the diagnostic tool for problem solving abilities for adults ${ }^{1}$, developed by Korea Educational Developmental Institute (2003) with Chronbach alpha of .86. The abilities to communicate were investigated by the diagnostic tool for communication abilities for college students ${ }^{4}$ developed by Lee(2003), with Chronbach alpha 
of .83. Paired t-test was used for the analysis of differences pre and post status in nursing ethical values and learning outcomes of the subjects, using the SPSS Program.

\section{Results}

\subsection{Demographic Characteristics of Participants}

Total number of participants of this study was 128 . $93.8 \%$ of the participants was female and 21.3 years old on average. 58.6\% of them were Christens and 57\% responded that they were active in student club activities. $89.1 \%$ answered that they have brother or sister and $52.3 \%$ said they had experienced a medical volunteering activity. $77.3 \%$ responded that they were highly satisfied with nursing major.

\subsection{Nursing ethical values}

As a result of the research, average nursing ethical value was $3.65 \pm 0.33$ before taking the course of nursing ethics. But, the nursing ethical value was changed to $3.75 \pm 0.33$ higher $(\mathrm{t}=-2.687, \mathrm{p}=0.008)$ after the debate teaching methods for 6 weeks Table 1. This mean that nursing students' point of views were moved to prefer deontology from utilitarianism. Jung(2012) said that ethic values of nursing student revealed a deontological attitude after CEDA debate ${ }^{6}$. This result was consistent with Jung(2012).

\subsection{Learning outcomes}

As a result of the research, average teamwork skill of the subjects was $3.89 \pm 0.39$, before taking a class. After applying the debate teaching methods, the average points changed to $3.94 \pm 0.45(\mathrm{t}=-1.366, \mathrm{p}=0.174)$. But this was not significant. The average problem solving ability

Table 1. Changes nursing ethical values after the debates teaching methods

\begin{tabular}{|l|c|c|c|c|}
\hline \multirow{2}{*}{ Variables } & \multicolumn{2}{|c|}{ Mean(SD) } & \multirow{2}{*}{$t$} & $p$ \\
\cline { 2 - 4 } & Pre & Post & & \\
\hline $\begin{array}{l}\text { Nursing ethical } \\
\text { value }\end{array}$ & $3.65(.33)$ & $3.75(.33)$ & -2.687 & 0.008 \\
\hline Teamwork skill & $3.89(.39)$ & $3.94(.45)$ & -1.366 & 0.174 \\
\hline $\begin{array}{l}\text { Problem solving } \\
\text { ability }\end{array}$ & $3.69(.42)$ & $3.79(.38)$ & -3.315 & 0.001 \\
\hline $\begin{array}{l}\text { Communication } \\
\text { ability }\end{array}$ & $3.70(.35)$ & $3.74(.36)$ & -1.536 & 0.127 \\
\hline
\end{tabular}

of the subjects was $3.69 \pm 0.42$, before taking a class. After changing teaching methods, the average points moved to $3.79 \pm 0.38$, higher, significantly $(t=-3.315$, $\mathrm{p}=0.001)$. This means that debate teaching methods concern students' problem solving ability, effectively. The average communication ability of the subjects was $3.70 \pm 0.35$, before taking a class. After changing teaching methods, the average points moved to $3.74 \pm 0.36$, higher $(\mathrm{t}=-1.536, \mathrm{p}=0.127)$. But this was not significant, too Table 1.

\section{Discussion}

\subsection{Nursing ethical values}

The results of this study showed that there was a statistically significant change in the nursing ethical values of the participants after 6-week debate period. The participants' ethical values turned more toward utilitarianism from deontology. The reason for this shift of nursing ethical values seems to be that the decision makers with the perspective of Kent's traditional deontology couldn't easily tackle ethically dilemmatic situations given to them, so they had a tendency to avoid such issues. Meanwhile, there were more students who took utilitarian approach to the ethical issues and it affected other participants, shifting the latter' ethical values easily to the former's side.

The finding of this study match with that of Jung et al.s study that demonstrated it was effective to use debate method for the ethics education of nursing students. Lee also reported that ethics education has a positive effect on the development of moral judgment of nursing students ${ }^{3}$. In the study of 000 , which researched the effect of group debate learning on ethics education, it was reported that change occurred in the students' bioethics ${ }^{10}$. According to the study of Moon, the participants' bioethics significantly improved after ethical education. Therefore, it can be inferred that the education of nursing ethics influences the awareness of bioethics ${ }^{11}$.

In their study, Jung et al. conducted CEDA-based debate sessions for 4 weeks ( 8 hours in total) and reported that the outcome was positive. However, they suggested replication study to verify the effectiveness of the debate learning due to the relative short period of experiment and additionally proposed other debate methods should be applied than $\mathrm{CEDA}^{6}$. This study employed pyramid debate, parliamentary debate and mock trial debate as well as CEDA and confirmed they were all effective. 
It demonstrates that using diverse methods of debate is effective for the education of nursing ethics.

Moral judgment is an ability to decide fairness, justice and moral rightness based on righteously established ethics and values. It is not born with but acquired through education. Therefore, a systematic education is necessary that helps learners improve their moral thinking by themselves through mature consideration and self-examination ${ }^{6}$. In this respect, it is a very excellent method to combine debate methodology to the education of nursing ethics.

\subsection{Learning outcomes}

The presents study demonstrated that when debate methods were applied to the education of nursing ethics, the average scores of teamwork skill, ability to solve problem and communication improved. However, only the increase of problem solving ability was statistically significant.

Yoo et al, reported that they applied a variety of teaching methods -such as lecturing with a text book, $\mathrm{Q}$ and $\mathrm{A}$ session class, use of audio-visual materials related to a topic, case studies, group discussion and presentation, and sharing of learners' opinions- to enhance the students' critical thinking in the education of nursing ethics, but there was no change in their tendency of critical thinking ${ }^{10}$.

Recently, the number of patients with complex disease has increased and medical system and ethics policies are rapidly changing. Under these circumstances, nursing ethics should be open as a full course in nursing curriculum and appropriate teaching methodology should be implemented to foster nurses with an ability to solve various nursing problems. Debate learning can be one of the most excellent methodologies.

Teamwork skill and communication ability upgraded slightly before the debate class, but these are not significantly. If we had a long period to debate about nursing issues, the results might be changed. It is well known that communication skill is key role to enhance the teamwork. If there is conflict in nursing problem circumstances, arguing over assignments, questioning every decision, complaining incessantly, arguing with coworkers in the presence of others. And nurses often refuse to attend or participate at meetings designed to address concerns, then complain about problems that nurses are not willing to help solve. Nurses are unstable, bringing their personal problems to work $^{12}$. It is suggested that another research with more large samples and long period for debates is repeated.

Debates including CEDA, Pyramid, mock court, panel discussion and parliamentary debate wasn't carried out without team-building. Problem solving ability might be improved through hearing various ideas from teammate. Debate teaching methods affected on nursing students' learning outcome moved to higher and helped enhancing problem solving ability.

\section{Conclusions}

This study was aimed to identify the effects of debated teaching methods on nursing ethical value and learning outcomes. Learning outcome included Teamwork skill, Problem solving ability, and Communication ability. Group debate facilitates nursing students in solving given ethical dilemmas that can arise in a clinical setting because they can approach the issues from various points of view. CEDA, parliamentary debate, pyramid debate and panel debate were chosen as debating methods in this study.

Debate teaching methods elevated students' nursing ethical vale and teamworkskill, problem solving ability, and communication ability. After the class, nursing students' view point was moved to deontology from utilitarianism. And problem solving ability was improved. The scores of teamwork skill and problem solving ability were slightly increased. It is suggested that another research with more large samples and long period for debates is repeated. Debate methods is a good teaching model and very useful for ethic class.

\section{References}

1. Korean Educational Developmental Institute (KEDI). A study on the developmental of life-skills: Communication, problem solving, and self-directed learning. Seoul: Korean Educational Developmental Institute. 2003.

2. LEE MA. The Efficacy of Ethics Education on the Moral Judgment of Nursing Students. Korean J Med Ethics. 2009; 12(2):177-88.

3. Lee SM. Relationships of Nurses' Teamwork Skills to Team Effectiveness in Nursing Units. Master's thesis, Catholic University of Pusan; 2013.

4. Lee SJ. The Effects of Action Learning Program on Nurses' Problem Solving and Communication Skills. Master's thesis, Chonnam National University; 2009.

5. Moon JR. Attitude on the withdrawal of meaningless lifesustaining treatment and ethical values of clinical nurses. Master's thesis, Catholic University of Pusan; 2013.

6. Jung HJ, Park HJ, and Jang IS. Effects of Nursing Ethics Education based upon CEDA Debates on Moral Judgment 
and Ethical Values. J Korean Acad Soc Nurs Edu. 2012; 18(2):248-58.

7. Burkhardt MA, Nathaniel AK. Ethics and Issues in Contemporary Nursing. $4^{\text {th }}$ Ed., 2014.

8. Ha JY, Kim DH, Hwang SK. The Perception of Biomedical Ethics in Nurses. J Korean Acad Soc Nurs Edu. 2009; 15(2):216-24.

9. Ann SH, Kim YS, Cho GC, Eom YR, Lee SH. Nursing ethical dilemmas nurses experienced and need for decision making manual. Korean Nurses Association. 2003.
10. Yoo MS, Park HS. Effects of Nursing Ethics Education on Bioethics Awareness and Critical Thinking Dispositions of Nurses. J Korean Bioethics Assoc. 2010; 11(1):51-60.

11. Moon MY, Jaung AH. Correlation Between the Nursing Practice and Consciousness of Biomedical Ethics of Nursing Students. J Korean Bioethics Assoc. 2012; 13(2):49-62.

12. Cohen MH. Professional Communication and Teamwork. Creative Nursing. 2008; 14(1):17-23. 